\title{
DOE STANDARD \\ GUIDE TO GOOD PRACTICES FOR EQUIPMENT AND PIPING LABELING
}

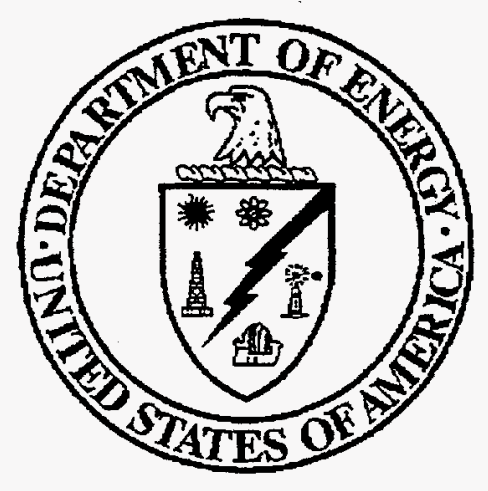

U.S. Department of Energy AREA FACR Washington, D.C. 20585 


\section{DISCLAIMER}

This report was prepared as an account of work sponsored by an agency of the United States Government. Neither the United States Government nor any agency thereof, nor any of their employees, make any warranty, express or implied, or assumes any legal liability or responsibility for the accuracy, completeness, or usefulness of any information, apparatus, product, or process disclosed, or represents that its use would not infringe privately owned rights. Reference herein to any specific commercial product, process, or service by trade name, trademark, manufacturer, or otherwise does not necessarily constitute or imply its endorsement, recommendation, or favoring by the United States Government or any agency thereof. The views and opinions of authors expressed herein do not necessarily state or reflect those of the United States Government or any agency thereof. 


\section{DISCLAIMER}

Portions of this document may be illegible in electronic image products. Images are produced from the best available original document. 
Change Notice No.1

DOE-STD-1044-93

December 1998

Guide to Good Practices for Equipment and Piping Labeling

\begin{tabular}{|l|l|}
\hline \multicolumn{1}{|c|}{ Page/Section } & \multicolumn{1}{c|}{ Change } \\
\hline $\begin{array}{l}\text { pg. A-4 / Table A-1/Arrange by System Name } \\
\text { column }\end{array}$ & $\begin{array}{l}\text { The following system name and code were } \\
\text { deleted: "Waste, Radioactive" and "RW." }\end{array}$ \\
\hline pg. B-4 & The first bullet was added. \\
\hline Concluding Material & $\begin{array}{l}\text { The Preparing Activity was changed from } \\
\text { NE -73 to EH-31. }\end{array}$ \\
\hline
\end{tabular}




\title{
FOREWORD
}

The purpose of this Guide to Good Practices is to provide Department of Energy (DOE) contractors with information that can be used to validate and/or modify existing programs relative to Conduct of Operations. This Guide to Good Practices is part of a series of guides designed to enhance the guidelines set forth in DOE Order 5480.19, Conduct of Operations Requirements for DOE Facilities.

\section{KEYWORDS}

\author{
Equipment Identification
}

Label 
DOE-STD-1044-93

INTENTIONALLY BLANK 


\section{TABLE OF CONTENTS}

FOREWORD

iii

1. INTRODUCTION $\ldots \ldots \ldots \ldots \ldots \ldots \ldots \ldots \ldots \ldots \ldots \ldots \ldots \ldots \ldots \ldots$

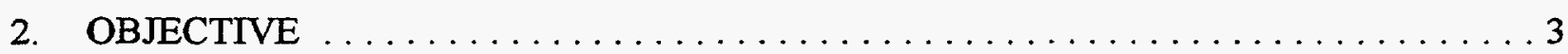

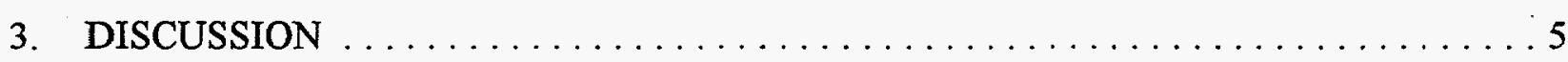

4. GOOD PRACTICES $\ldots \ldots \ldots \ldots \ldots \ldots \ldots \ldots \ldots \ldots \ldots \ldots \ldots \ldots$

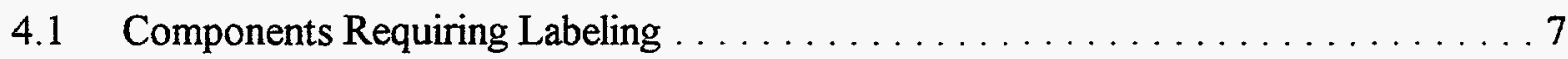

4.2 Label Information $\ldots \ldots \ldots \ldots \ldots \ldots \ldots \ldots \ldots \ldots \ldots \ldots \ldots$

4.3 Label Placement . . . . . . . . . . . . . . . . . . . . . . . . 9

4.4 Replacing Labels $\ldots \ldots \ldots \ldots \ldots \ldots \ldots \ldots \ldots \ldots \ldots \ldots \ldots$

4.4.1 Identifying Lost or Damaged Labels $\ldots \ldots \ldots \ldots \ldots \ldots \ldots$

4.4 .2 Providing New Labels $\ldots \ldots \ldots \ldots \ldots \ldots \ldots \ldots \ldots \ldots \ldots$

SUPPLEMENTAL RESOURCES $\ldots \ldots \ldots \ldots \ldots \ldots \ldots \ldots \ldots \ldots$

APPENDIX A

LABEL INFORMATION $\ldots \ldots \ldots \ldots \ldots \ldots \ldots \ldots \ldots \ldots \ldots \ldots \ldots \ldots$

APPENDIX B

COLOR CODING $\ldots \ldots \ldots \ldots \ldots \ldots \ldots \ldots \ldots \ldots \ldots \ldots \ldots \ldots \ldots \ldots$

APPENDIX C

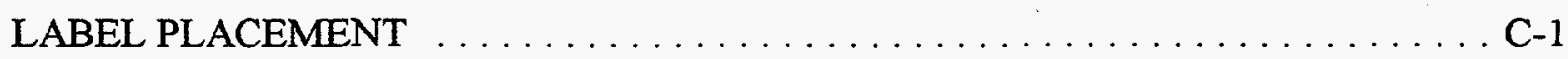


DOE-STD-1044-93

INTENTIONALLY BLANK 


\section{GUIDE TO GOOD PRACTICES FOR EQUIPMENT AND PIPING LABELING}

\section{INTRODUCTION}

This Guide to Good Practices is written to enhance understanding of, and provide direction for, "Equipment and Piping Labeling," Chapter XVIII of Department of Energy (DOE) Order 5480.19, Conduct of Operations Requirements for DOE Facilities. The practices in this guide should be considered when planning or reviewing labeling programs. Contractors are advised to adopt procedures that meet the intent of DOE Order 5480.19.

"Equipment and Piping Labeling" is an element of an effective Conduct of Operations program. The complexity and array of activities performed in DOE facilities dictate the necessity for a coordinated labeling program to promote safe and efficient operations. 
DOE-STD-1044-93

INTENTIONALLY BLANK 


\section{OBJECTIVE}

The objective and criteria are derived from DOE Order 5480.19. They are intended to aid each facility in meeting the intent of the order.

An equipment labeling program is established and maintained to ensure that facility personnel are able to positively identify the equipment they operate.

\section{Criteria:}

a. Equipment, components, and piping that require labeling are identified by the facility.

b. Label information meets regulatory requirements and is consistent with facility procedures.

c. Label materials and means of attachment are compatible with the components and environment where they are used.

d. Labels are properly placed and oriented to enhance readability and component identification.

e. Checks to verify that labels are correct are included in designated operating procedures.

f. Procedures are established to replace lost or damaged labels and to acquire new labels when needed. 
DOE-STD-1044-93

INTENTIONALLY BLANK 


\section{DISCUSSION}

A well-established and maintained labeling program is essential for safe, reliable operation and maintenance of DOE facilities. During the period December 1990 through August 1992, DOE facilities reported more than 40 occurrences in which ineffective or incorrect labeling of equipment and piping contributed to errors in implementation of lockout/tagout, maintenance on the wrong equipment, inadvertent equipment startup, failure of designated safety or backup systems, or improper operation of facility equipment. The consequences, or potential consequences, of these occurrences include personnel injury, equipment damage, release of hazardous or toxic material, and loss of proper control of nuclear materials and processes.

An effective labeling program will clearly identify each component required in the operation of the facility, warn of specific hazards, and clearly identify emergency equipment. Effective labeling will enhance training effectiveness and help reduce operator and maintenance errors resulting from incorrect identification of facility equipment. Effective labeling will help reduce personnel exposure to radiation or hazardous materials by reducing the time spent identifying components. Piping labels that identify the contents, or at least the type of hazard represented by the contents, and the normal direction of flow will aid in preventing or mitigating leaks and spills. Labels on electrical equipment identifying the applicable feeder panel or breaker will aid in isolation for lockout/tagout, and will aid in quick and accurate response to equipment emergencies.

Labels should be designed to present information in a manner that will enhance operations and maintenance. The equipment names and number designations used on labels should be consistent with those used in procedures and drawings. Label size, placement, arrangement, fabrication materials, color coding, lettering size and type style can all affect the usability of labels. The Electric Power Research Institute (EPRI) report, EPRI NP-6209, Effective Plant Labeling and Coding, contains research data and illustrations showing how to use labels effectively in control room and plant environments.

To remain effective, the labeling program must be an ongoing process. Maintenance activities involving removal or replacement of equipment may also result in loss or misplacement of component labels. Spills, passage of time, or other environmental factors may cause labels to become damaged or unreadable. Equipment modifications may result in new label requirements. Facility procedures should provide instructions for temporarily labeling components, and a central point of contact to ensure timely response to ongoing labeling requirements. 
DOE-STD-1044-93

INTENTIONALLY BLANK 


\section{GOOD PRACTICES}

\subsection{Components Requiring Labeling}

Facilities should establish written guidelines for labeling components, systems, and hazards that personnel may be expected to encounter in the course of their work. The following items should be considered for the labeling program:

- Cabinets, including internal components (relays, terminals, etc.)

- Circuit breakers $(4.16 \mathrm{kV}, 480 \mathrm{~V}$, 120VAC/DC, etc.)

- Electrical busses

- Electrical distribution and lighting panels

- Emergency equipment (fire alarm stations, eye wash stations, etc.)

- Equipment components (motors, valves, pumps, etc.)

- Equipment subsystems

- Exits, evacuation routes

- Facility location codes (buildings, columns/rows, floors/elevations)

- Floor drains
- Fluid and gas lines (piping, ventilation ducts, etc.)

- Fire protection systems and equipment

- Fuse blocks or fuse locations

- Gauges, meters, and other indicators

- Major equipment systems (e.g., emergency generator, heating and air conditioning system, etc.)

- Motor control centers

- Protective equipment, first aid equipment, safety devices

- Room doors (list major equipment inside hazardous or radiation areas)

- Safety hazards and warnings

- Storage containers, cabinets, storage spaces

- Test equipment, special tools

\subsection{Label Information}

A label should provide a concise and meaningful verbal description of the function (noun name) of an item being identified, and a unique alphanumeric code identifying the system and component, as shown in Appendix A. Noun names and alphanumeric codes used on labels should be consistent with those used in all facility procedures, round sheets, alignment checklists, engineering drawings, and piping and instrument diagrams. Information on control panel labels should be consistent with the information on labels attached to the equipment being controlled. Alphanumeric codes should be developed in a manner that will aid personnel in consistently identifying the correct component and prevent misidentification. For example, two parallel motor 
control centers may be identified as MCC-1A and MCC-1B, but identifying them as MCC-1A and MCC-1-1A may lead to confusion.

Abbreviations and acronyms used on labels should come from the facility's approved list of abbreviations and acronyms, and should be commonly understood. Example lists of system designator codes and component function codes are shown in Appendix A.

The following additional guidelines should be considered when developing labels for specific components.

- Labels installed on electrical cabinets, panels, and equipment should indicate the maximum voltage present.

- Labels placed outside doors to rooms should identify the major equipment items contained within.

- Labels for electric motors and other electrical equipment should identify the power supply (e.g., distribution panel, circuit breaker, etc.).

- Labels for pneumatic actuators should identify the respective isolation valves.

- Labels on piping should indicate the contents (or hazard) and the normal flow direction. Piping containing radioactive fluids, toxic materials, or explosive gases should be uniquely marked. (Appendix B identifies a standard method for labeling piping using color codes to indicate the level of hazard.)

Color coding or shape coding can enhance the information presented on a label. For example, facilities having multiple units or parallel trains of equipment may color code labels using a distinctive color for each unit or equipment train, or they may code each unit with a unique label shape (e.g., unit A labels are triangular, unit B labels are rectangular, unit $\mathrm{C}$ labels are round). These practices have been shown to reduce misidentification.

Color coding can also be used to identify functional groups of components, such as components connected to the emergency power bus. When color coding is used, it should be applied consistently and have only one meaning for each color or 
combination of colors. Appendix B describes several applications of color coding for labels, control panels, and components.

In some facilities, bar coding is added to equipment labels to facilitate automated data taking or maintenance tracking. Facilities involved in extensive relabeling of existing equipment or installation of new equipment systems may find it worthwhile and cost effective to add bar coding.

\subsection{Label Placement}

Labels should be placed on or near the components being identified in a manner that clearly associates the label with its respective component. Appendix $\mathrm{C}$ shows how the method used when applying labels can affect the operator's ease of use and the accuracy of identification.

Labels for components should be permanently attached to the components (e.g., attached to the valve yoke, not to a removable part such as the handwheel) in a way that will not interfere with the normal operational use or testing of the component. Valves operated by reach rods or chains, or other remotely operated components, should have an additional label installed at the operating device. Labels for chain operators should be attached to a small piece of tubing through which the chain passes, so the label always remains at the bottom of the chain loop. If the valve is difficult to be seen from the operating location, the label should indicate the open and close direction for the chain or other operator.

Label materials (including adhesives and other means of attachment) should be compatible with the components and environment where they are used. Labels made with embossed plastic tape frequently curl and fall off the panels to which they have been attached. Metal labels or wire attachments made of dissimilar metals can cause galvanic corrosion of the component, label, or attachment device. Use of adhesives containing chlorides can cause corrosion of stainless steel components.

High-temperature, humidity, chemical, or radiation environments may preclude the use of certain label materials.

Labels should normally be constructed of non-reflective materials. This helps ensure readability of the label under a variety of lighting conditions. Labels that must be read in dim light or during blackout conditions may require the use of reflective or phosphorescent materials. 
If possible, the text of all labels should be oriented as shown in Figure 1a. Labels for vertical runs of piping and conduit may require that the label be oriented vertically. When vertical labels are necessary, the text should be oriented as shown in Figure 1b. Labels should never be oriented like those shown in Figure 1c.

\begin{tabular}{|l|l|l|}
\hline ZN-690 & \multicolumn{1}{|l|}{$\mid$\begin{tabular}{|l|}
\hline \\
\hline
\end{tabular}} & \\
\hline $\begin{array}{l}\text { Figure la. Preferred } \\
\text { orientation for all labels. }\end{array}$ & $\begin{array}{l}\text { Figure lb. Acceptable } \\
\text { orientation for vertical } \\
\text { labels. }\end{array}$ & $\begin{array}{l}\text { Figure lc. Unacceptable } \\
\text { label orientation. }\end{array}$ \\
\hline
\end{tabular}

Labels should be readable from the normal operating location or position (i.e., an operator should not be required to manipulate the label before reading it). The character height of label text should be based on the reading distance, available illumination, and importance of the information.

- The minimum character height for good illumination environments can be determined by multiplying the nominal reading distance by 0.004 . For example, if the nominal reading distance for an operator standing directly in front of a panel is 28 inches, the minimum label character height would be 0.112 inches $(0.004 \times 28$ inches).

- The preferred height for label characters giving critical information or in areas of adverse illumination is 0.006 times the reading distance. For example, if the reading distance is 28 inches, the preferred character height would be 0.168 inches $(0.006 \times 28$ inches). 


\subsection{Replacing Labels}

\subsubsection{Identifying Lost or Damaged Labels}

Facilities should establish procedures to ensure that missing, damaged, or incorrect labels are promptly replaced. Since labels may be removed or misplaced during maintenance activities, facility procedures should require operators to verify labels when the equipment is returned to service. Operators performing component alignments or rounds should verify that labels are present, readable, and undamaged. A column can be added to valve line-up sheets or system alignment checklists to ensure that label condition and accuracy are checked during system line-ups. Checks may also be added to preventive maintenance procedures (PMs), or other procedures, to ensure that components are correctly labeled.

Operators should watch for use of informal labeling methods (e.g., black marking pen) as these may represent places where formal labeling should be applied.

\subsubsection{Providing New Labels}

The operations supervisor (or other designated management authority) should review and approve all requests for new or replacement labels. Labeling requirements should also be evaluated during the planning of design changes or temporary modifications. Conflicts involving component identification (e.g., inconsistent component numbers or names used in procedures or drawings) should be resolved before labels are approved.

If a new label cannot be immediately provided, a temporary label should be installed until a correct permanent label can be obtained. All labels should be installed by personnel knowledgeable of the components and their function in the system to prevent inadvertent equipment operation during label installation, and to prevent interference with normal component operation. The attachment of temporary or permanent labels should be independently verified to ensure that the label is properly attached to the correct component and all the label information is correct. 
Facilities may find it advantageous to obtain label-making equipment, so replacement labels can be produced on site. The EPRI report, Effective Plant Labeling and Coding, cited in Section 3, discusses various methods for providing replacement labels and estimates the delay time and the cost associated with each. 
DOE-STD-1044-93

\section{SUPPLEMENTAL RESOURCES}

The following sources provide additional information pertaining to topics discussed in this Guide to Good Practices:

DOE Order 5480.19. Conduct of Operations Requirements for DOE Facilities.

DOE Order 5480.19, Chapter XVIII, “Equipment and Piping Labeling."

Electric Power Research Institute, EPRI NP-6209, Effective Plant Labeling and Coding (1989).

American National Standards Institute, ANSI A 13.1-1996, Scheme for the Identification of Piping Systems. 
DOE-STD-1044-93

INTENTIONALLY BLANK 
DOE-STD-1044-93

APPENDIX A

LABEL INFORMATION

A-1 
DOE-STD-1044-93

INTENTIONALLY BLANK

A-2 


\section{LABEL INFORMATION}

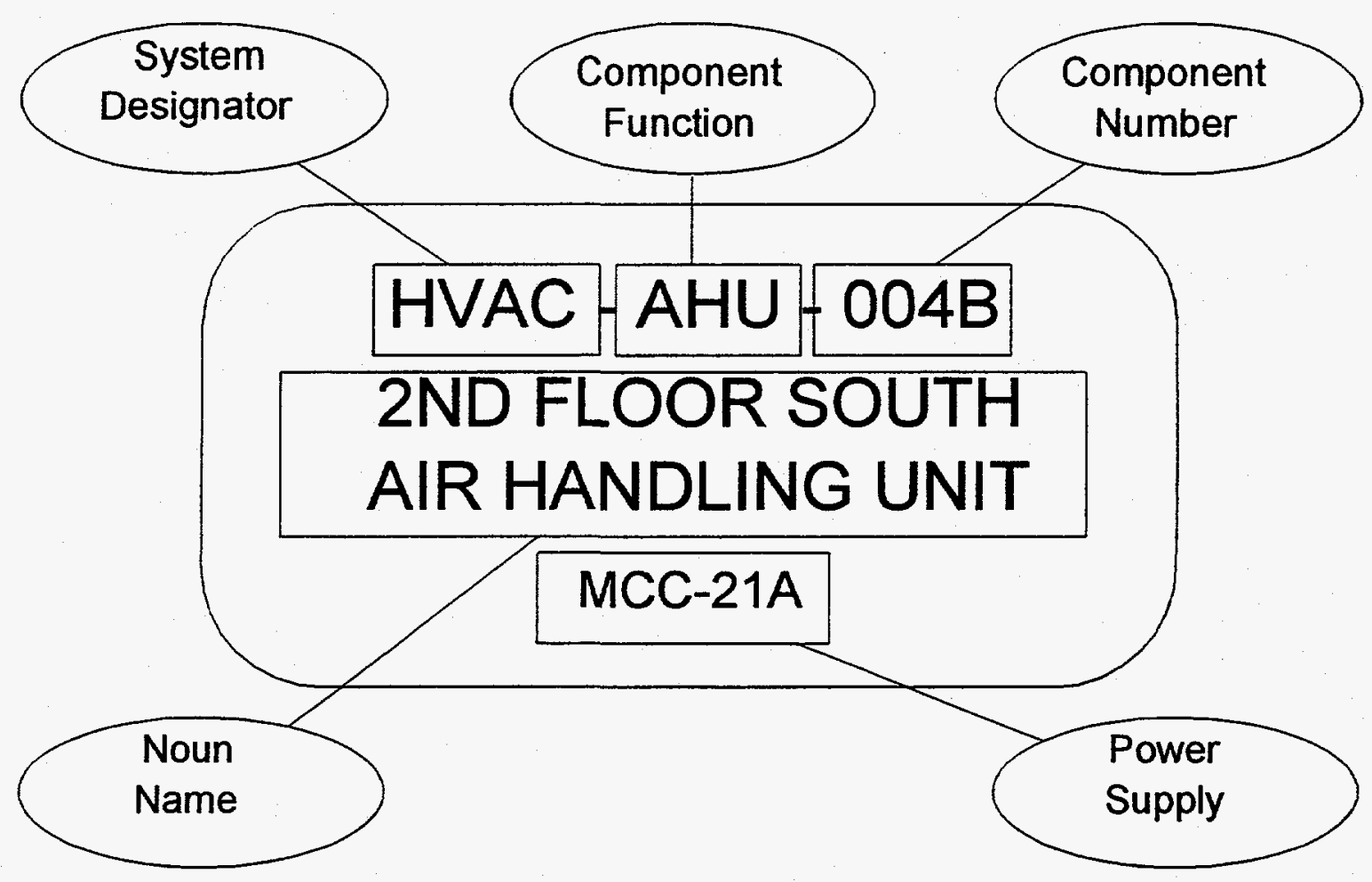

Figure A-1. Label Information

Labels should provide a concise and meaningful verbal description of the function (noun name) of the item being identified. Labels should also provide a unique alphanumeric code identifying the system and the component. In some facilities, particularly where duplicate systems or parallel trains of equipment are used, additional identifying information may be required to ensure that each label uniquely identifies a single component.

Noun names and alphanumeric codes used on labels should be consistent with those used in procedures, drawings, and other facility documents. Any abbreviations or acronyms used in noun names, system designator codes, or component function codes should be standardized, commonly understood, and identified on the facility approved list. It may be helpful to list systems and components by name and by designator to make it easier for personnel to locate the correct name associated with a label code, as illustrated in the following tables. 
Table A-1. System Designator Codes

Arranged by System Name

System Name

Air, Compressed

Air, Instrument

Electrical, Low-Voltage

( $\leq 240 \mathrm{~V})$

Electrical, Medium-Voltage

$(>240 \mathrm{~V}, \leq 4.16 \mathrm{kV})$

Fire Protection

Heating, Ventilation, and Air

Conditioning

Steam, Heating

Steam, High Pressure

Waste, Process Liquid

Waste, Sanitary

Water, Deionized

Water, Domestic $\frac{\text { Code }}{\mathrm{CA}}$

IA

ELLV

ELMV

FPS

HVAC

HTS

HPS

LPW

SWR

DIW

DW

\section{Arranged by Designator}

Code

CA

DIW

DW

ELLV

ELMV

FPS

HPS

HTS

HVAC

IA

LPW

SWR
System Name

Air, Compressed

Water, Deionized

Water, Domestic

Electrical, Low-Voltage $(\leq 240 \mathrm{~V})$

Electrical, Medium-Voltage

$(>240 \mathrm{~V}, \leq 4.16 \mathrm{kV})$

Fire Protection

Steam, High Pressure

Steam, Heating

Heating, Ventilation, and Air

Conditioning

Air, Instrument

Waste, Process Liquid

Waste, Sanitary

Table A-2. Component Function Codes

\section{Arranged by Component Function}

Component Function

Air Handler

Annunciator

Circuit Breaker

Compressor

Condenser

Damper

Heat Exchanger

Indicator, Current (Electric)

Indicator, Flow

Indicator, Voltage

Motor Control Center

Pump

Transformer

Valve, Air-Operated

Valve, Motor-Operated
Code

AHU

ANN

$\mathrm{CB}$

CMP

COND

DMP

HX

II

FI

EI

MCC

PMP

XFMR

AOV

MOV

\section{Arranged by Code}

Code

AHU

ANN

AOV

CB

CMP

COND

DMP

EI

FI

$\mathrm{HX}$

II

MCC

MOV

PMP

XFMR
Component Function

Air Handler

Annunciator

Valve, Air-Operated

Circuit Breaker

Compressor

Condenser

Damper

Indicator, Voltage

Indicator, Flow

Heat Exchanger

Indicator, Current (Electric)

Motor Control Center

Valve, Motor-Operated

Pump

Transformer 
DOE-STD-1044-93

APPENDIX B

COLOR CODING

B-1 
DOE-STD-1044-93

\section{INTENTIONALLY BLANK}




\section{COLOR CODING}

Color coding may be used in a number of ways to enhance the labeling of equipment and piping, as discussed below. When color coding is used, it should be applied consistently and have only one meaning for each color or combination.

\section{Highlighting Critical Component Controls or Groups of Controls}

One common use of label color coding is to provide easy recognition of critical controls, such as emergency stop or emergency shutdown controls. The use of red-on-white or white-on-red labels for these controls can set them apart from the standard labels used on the remainder of the control panel. To further accentuate critical controls or groups of controls, red functional demarcation lines can be used in association with red labels.

\section{Associating Related Controls and Displays}

The design of some control panels places gauges, meters, and other quantitative displays on an upper section of the panel and the associated controls on the lower section of the panel. Color coding can be used to help operators rapidly make the correct associations between control-display pairs. Methods include:

- Color-coded display bezels or labels, with matching color control handles or labels

- Color-coded paint patches on the control panel surface surrounding displays and controls.

\section{Showing Functional Demarcation of Controls}

Functionally related groups of control panel components can be identified by using taped demarcation lines or the "paint patch" or "color patch" method. When using taped demarcation lines, standard operating controls may be grouped using one color (e.g., black lines), critical controls using another (e.g., red lines), and annunciator controls using a third (e.g., orange or yellow lines), as illustrated in Figure B-1. The "paint patch" or "color patch" method (see Figure B-2) usually consists of a different color background on the control panel for each system, matching the paint colors used on facility components and piping.

Use of demarcation lines that are too bold, or extensive use of color in either of the above methods, can result in a control panel that is visually overwhelming. Consultation with graphic arts or visual communication arts personnel may help avoid problems in this area. Facilities 
choosing to use color coding may benefit from testing on a full-scale mockup before applying the coding system to control panels and components.

\section{Preventing Wrong-Unit, Wrong-System, or Wrong-Train Errors}

Wrong-unit errors can occur in the performance of operations or maintenance when identical components are used in parallel units. To reduce the errors, a unit color code can be applied to the following:

- Labels

- Walls

- Equipment bases, pedestals, and curbing

- Valve handwheels
- $\quad$ Floors

- Doors

- Stencil marking backgrounds

- $\quad$ Paper used for procedures or other unit-specific documents

Errors in identification also occur when similar or identical components are used in more than one system (e.g., portions of compressed air, fuel oil, lube oil, and cooling water systems may have similar piping and components), or when redundant equipment trains are installed (e.g., identical equipment may be installed in safety monitoring trains $\mathrm{A}$ and $\mathrm{B}$ ). Color-coded labels and other color-coding methods listed above may be applicable to systems and equipment trains. In addition, some facilities have applied color-coded paint to all painted components of designated systems; for example, all piping and components of the compressed air system are painted blue, the lube oil system is painted orange, the steam system is painted tan, etc.

\section{Identifying Hazards in Piping Contents}

A standard published by the American National Standards Institute, Scheme for the Identification of Piping Systems, ANSI A 13.1-1996, specifies a method for identifying the contents and hazards in piping systems. A standard method of identification is particularly important when components in piping systems may be operated or manipulated by personnel from outside the facility, such as firefighters or outside maintenance personnel. The standard identifies the following practices for labeling piping systems:

- The legend (text) of the label must identify the contents of the piping and the hazard (e.g., "hot water," "air - 100 psig," "sulfuric acid," etc.) 
- Arrows must be used with labels to indicate the direction of flow

- The label and arrow, or the pipe itself, should be color-coded to indicate the contents and level of hazard. The following color codes have been identified for this purpose:

\section{Piping Contents}

Materials inherently hazardous

(e.g., flammable, chemically active, toxic, dangerous temperatures or pressures, radioactive)

Low-hazard liquids or liquid admixtures near ambient temperature and pressure

Low-hazard gases or gaseous admixtures near ambient temperature and pressure

Fire quenching materials (e.g., water, foam, $\mathrm{CO} 2$, Halon, etc.)

\section{Label Color}

Yellow

Green

White

Blue

White

Red

White

\section{$\underline{\text { Legend Color }}$}

Black 


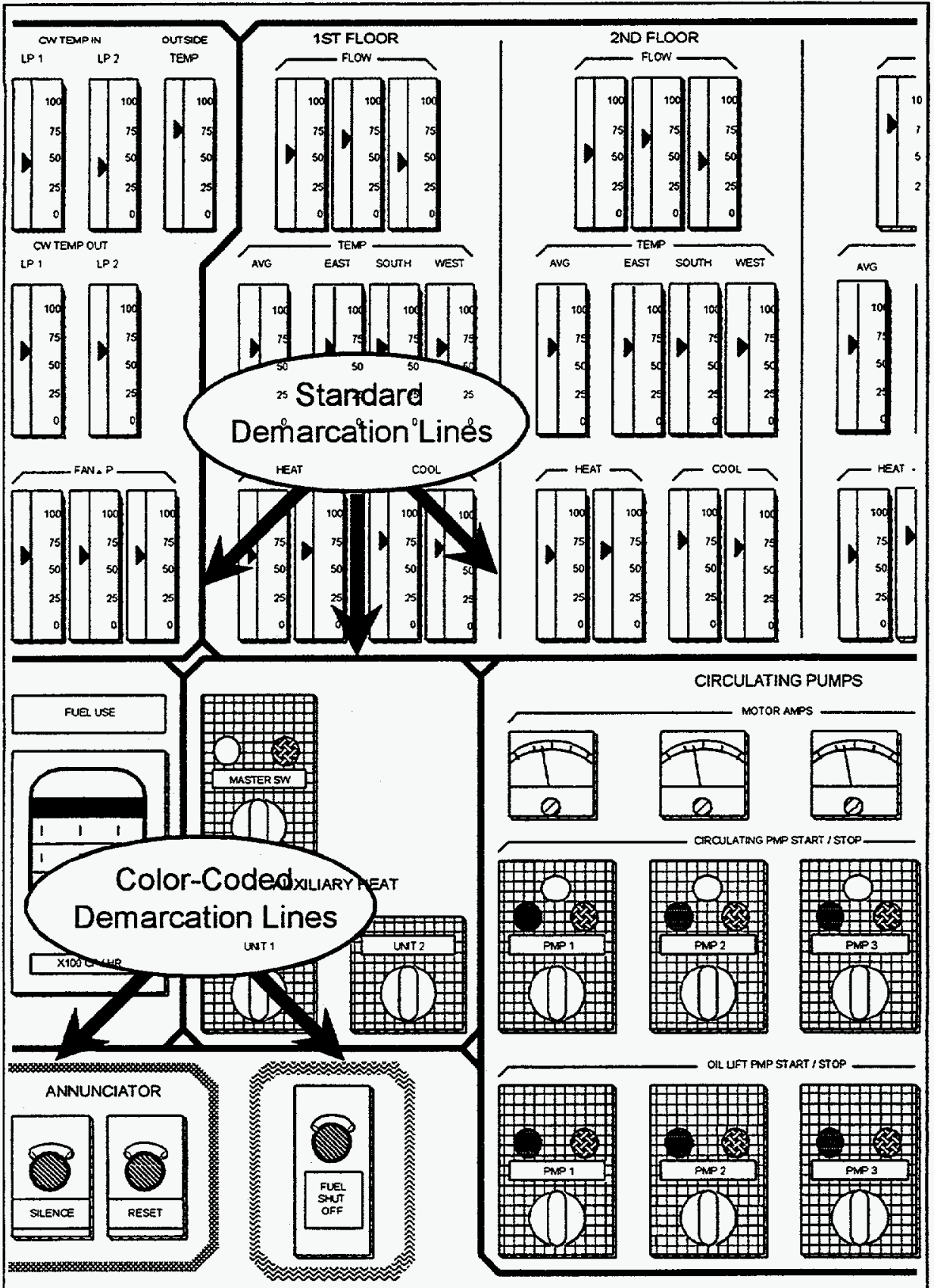

Figure B-1. Demarcation lines on a control panel. 


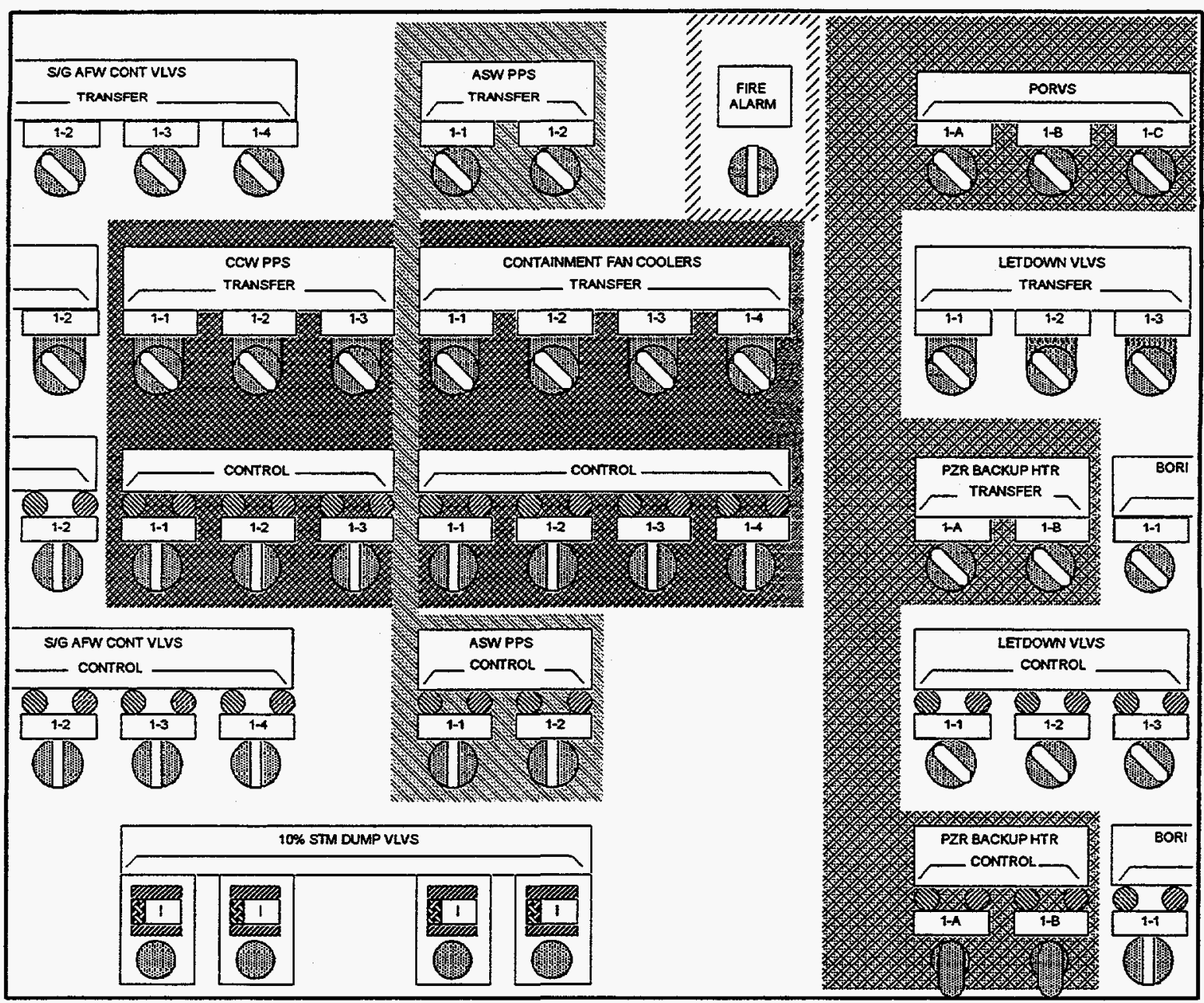

Figure B-2. Color patch method on a control panel. 
DOE-STD-1044-93

INTENTIONALLY BLANK

B-8 
DOE-STD-1044-93

APPENDIX C

LABEL PLACEMENT

C-1 
DOE-STD-1044-93

INTENTIONALLY BLANK

C-2 


\section{LABEL PLACEMENT}

Labels should be placed on or near the components being identified in a manner that clearly associates the label with its respective component and removes any ambiguity. Labels on control panels should be consistently placed above, below, or on components so that the operator is conditioned to finding and identifying information accurately. However, even when labels are placed consistently above or below components, the results can be confusing, as shown in Figure C-1.

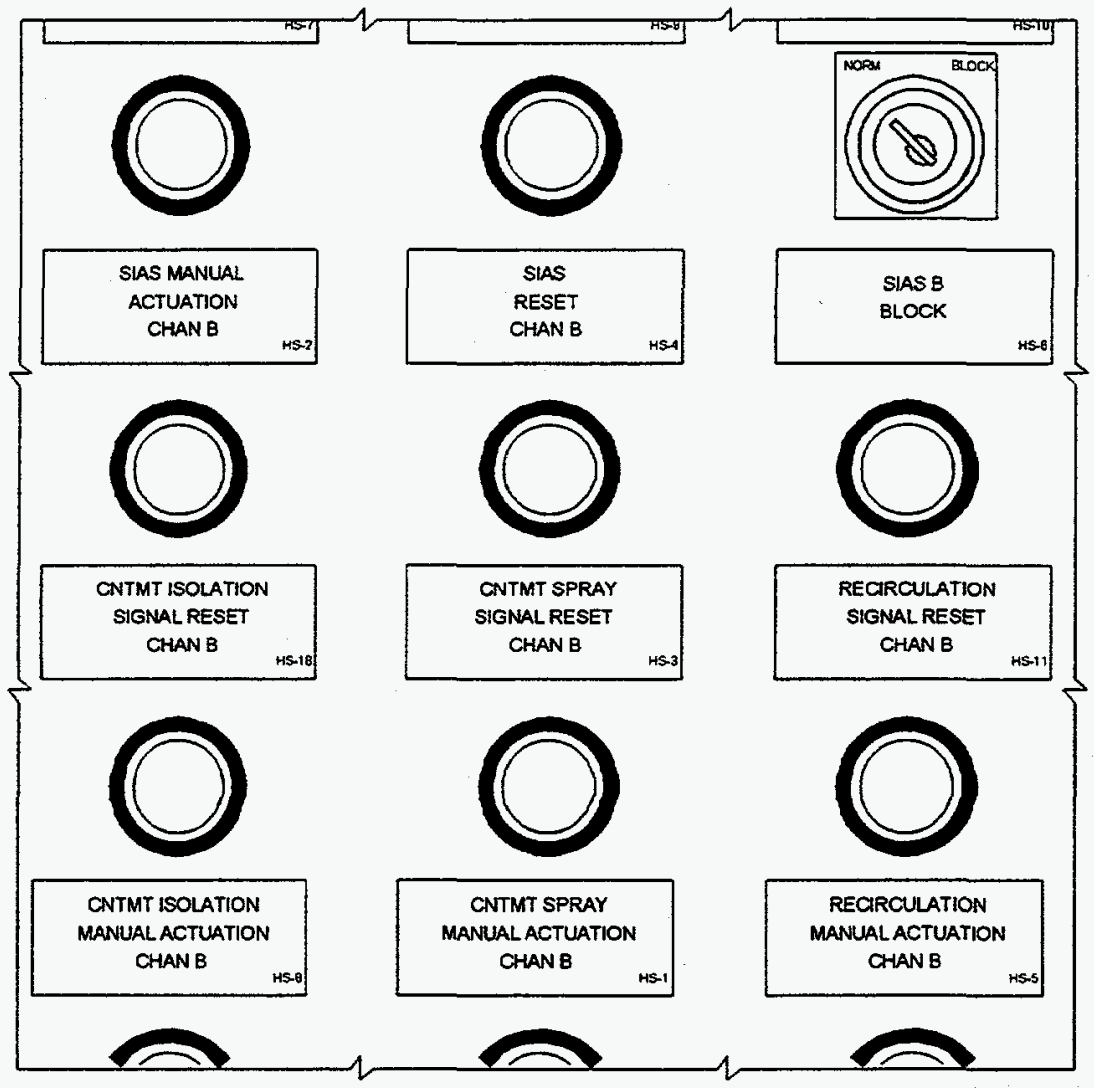

Figure C-1. Labels evenly spaced between components.

To accurately identify the correct label with each component in the portion of the control panel illustrated above, the operator would be required to search for indications of the labeling system used, by checking the top of the panel, the bottom of the panel, or a separate legend. This increases the chance of identification errors.

Where control panels contain many rows or columns of equally spaced components and labels, the facility can reduce the risk of misidentification by "connecting" the labels to the components they identify using brackets or tie lines, as shown in Figure C-2. 


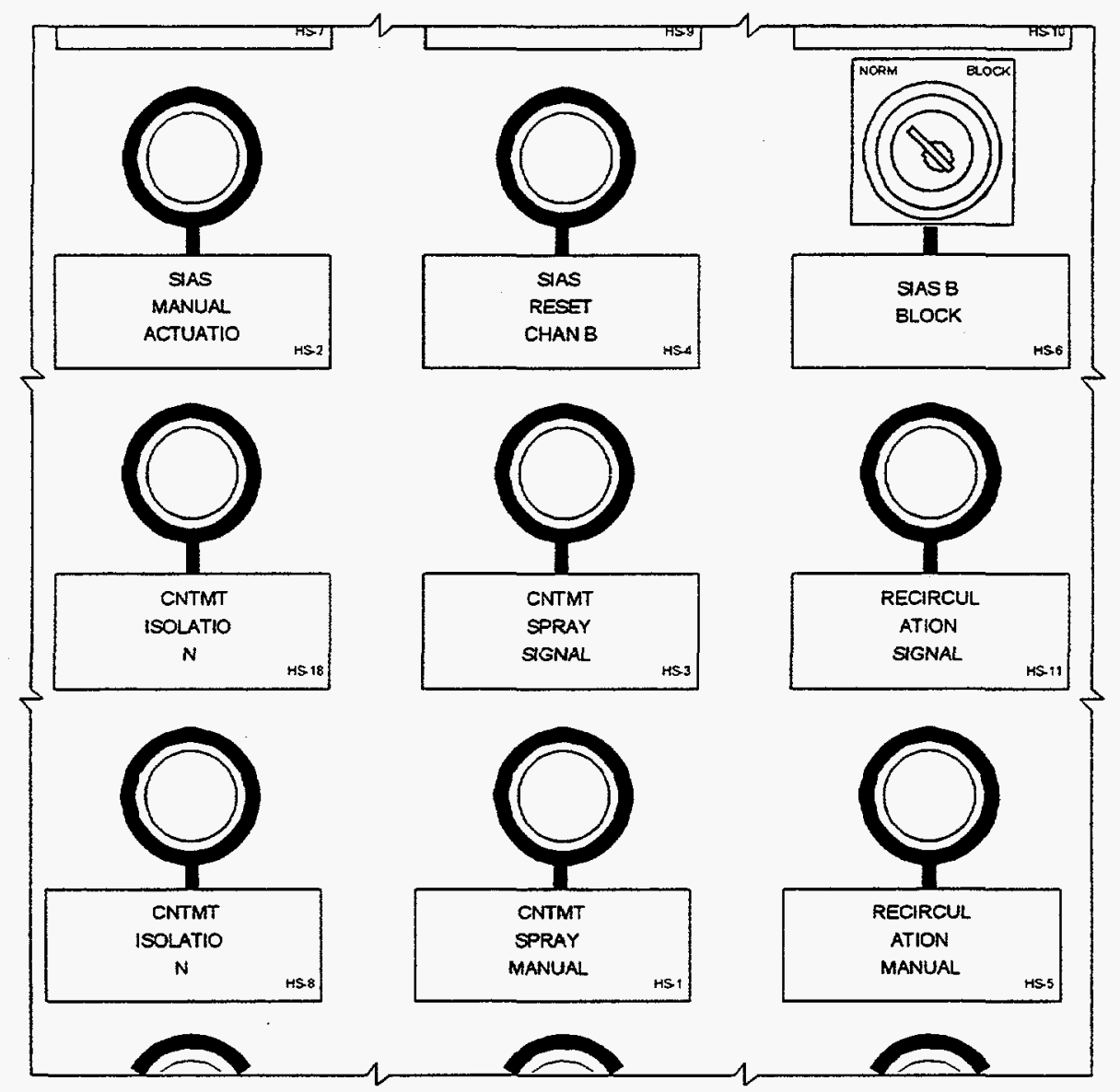

Figure C-2. Labels tied to components.

A better approach to labeling control panels is to place each label closer to the component it identifies than to any other component. The label for a control device (e.g., switch) should be placed above the control so the operator's hand does not block view of the label when operating the control. This method is illustrated in Figure C-3. 


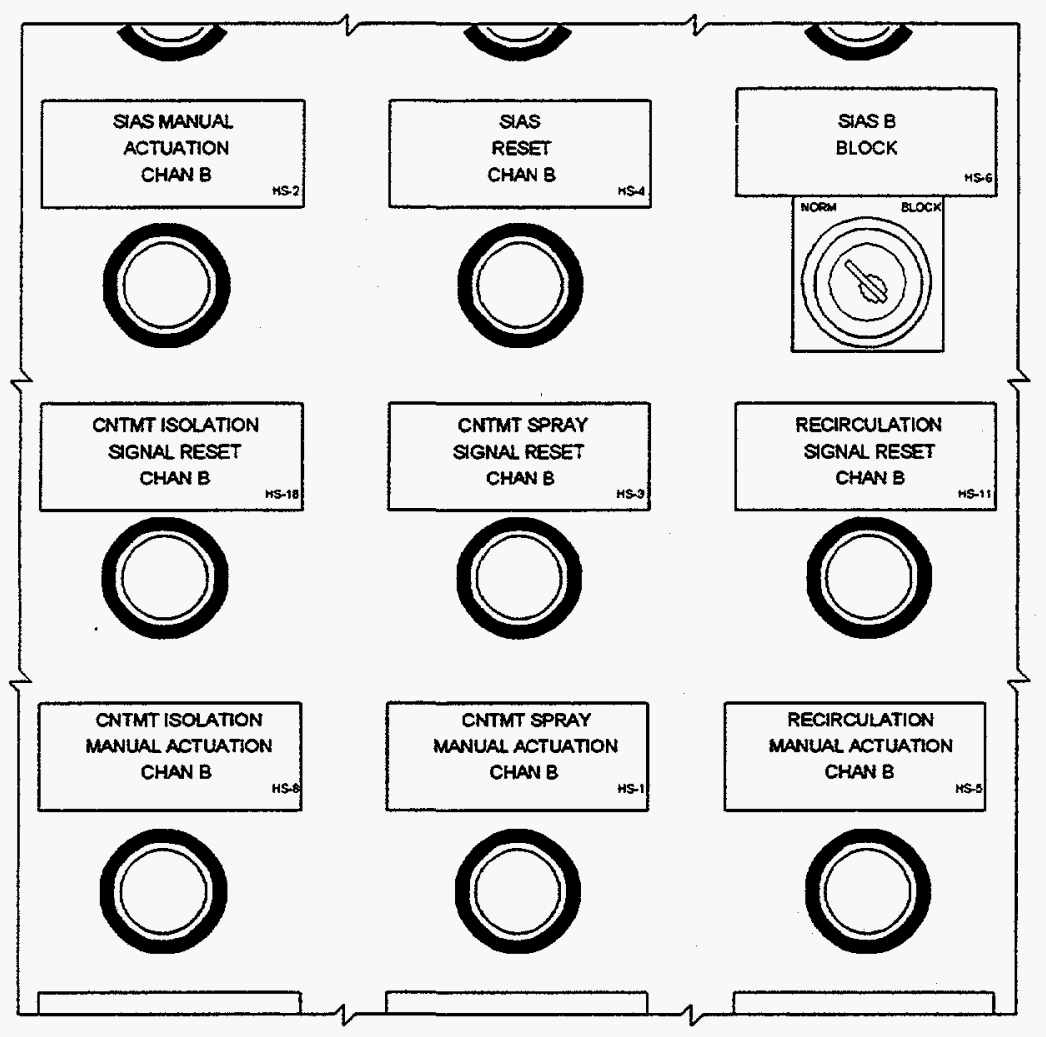

Figure C-3. Labels placed near the components they identify.

A final refinement for control panel labeling is the design of escutcheon plates, i.e., labels that enclose or surround each control panel device. These plates may be simple shapes, or they may be designed as graphic illustrations of the component being monitored or controlled, as shown in Figures C-4 and C-5.
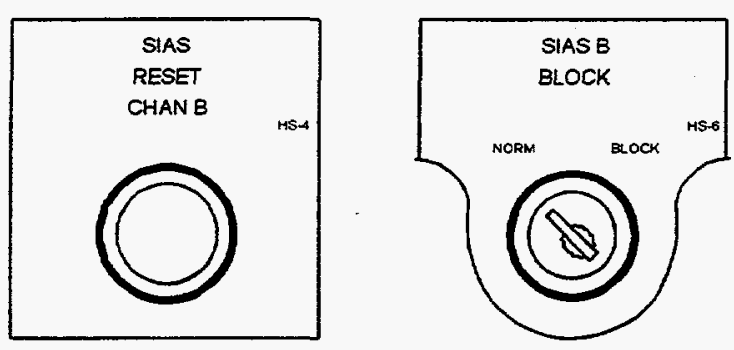

Figure C-4. Simple escutcheon plate labels. 

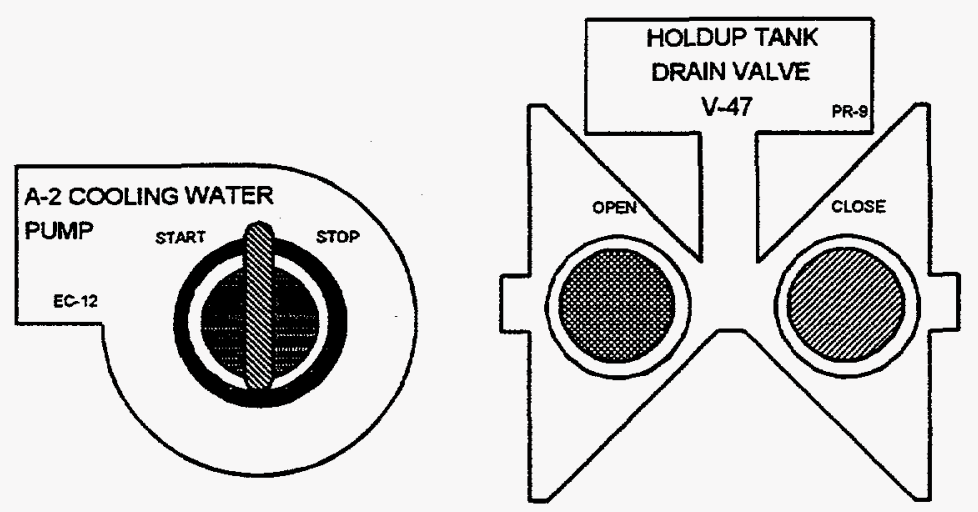

Figure C-5. Graphic escutcheon plate labels. 


\section{CONCLUDING MATERIAL}

Review Activities:

DOE

DP

$\mathrm{EH}$

EM

ER

NE

NS
Preparing Activity:

DOE-EH-31

Project Number:

FACR-0006 


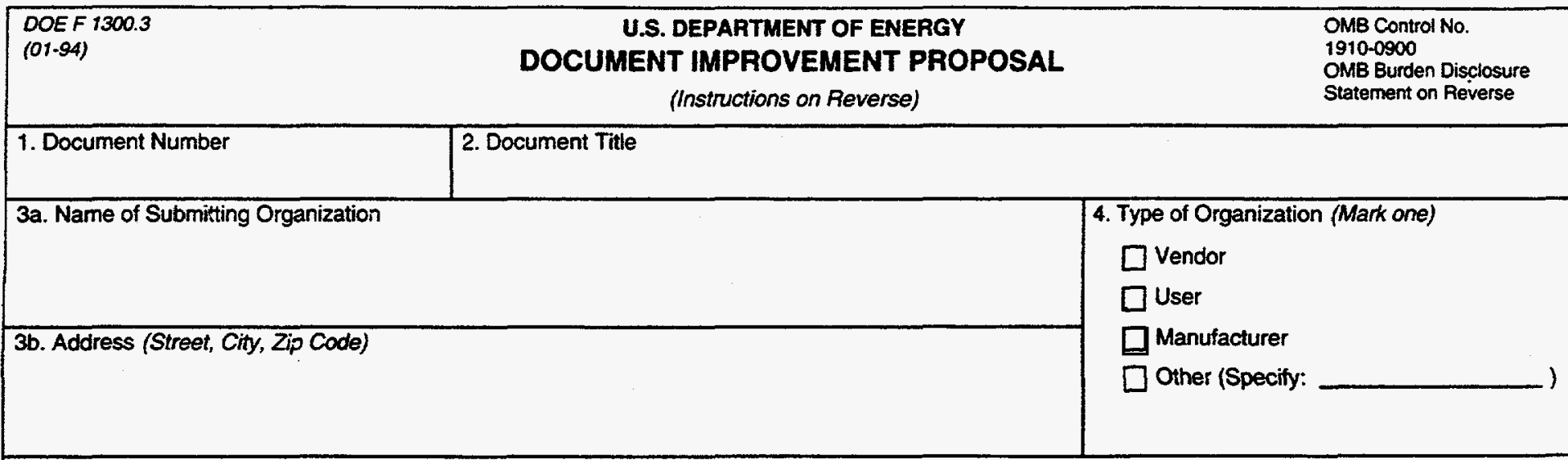

\section{Problem Areas (Aftach extra sheets as needed.)}

a. Paragraph Number and Wording

b. Recommended Wording

\section{c. Reason/Rationale for Recommendation}

6. Remarks

7a. Name of Submitter (Last, First, MI)

7b. Work Telephone Number (Include Area Code)

7c. Mailing Address (Street, City, State, Zip Code)

8. Date of Submission 
INSTRUCTIONS: In a continuing effort to improve the U.S. Department of Energy (DOE) Technical Standards, this form is provided for use in submitting comments and suggestions for improvements. All users of DOE Technical Standards are invited to provide suggestions. This form may be detached, folded along the lines indicated, taped along the loose edge (DO NOT STAPLE) mailed to the address indicated or faxed to (615) 574-0382.

1. The submitter of this form must complete blocks 1 through 8.

2. The Technical Standards Program Office (TSPO) will forward this form to the Preparing Activity. The Preparing Activity will reply to the submitter within 30 calendar days of receipt from the TSPO.

NOTE: This form may not be used to request copies of documents, nor to request waivers, deviations, or clarification of specification requirements on current contractors. Comments submitted on this form do not constitute or imply authorization to waive any portion of the referenced document(s) or to amend contractual requirements.

\section{OMB Burden Disclosure Statement}

Public reporting burden for this collection of information is estimated to average 30 minutes per response, including the time for reviewing instructions, searching existing data sources, gathering and maintaining the data needed, and completing and reviewing the collection of information. Send comments regarding this burden estimate or any other aspect of this collection of information, including suggestions for reducing this burden, to Office of Information Resources Management Policy, Plans, and Oversight, Records Management Division, HR-422 - GTN, Paperwork Reduction Project (1910-0900), U.S. Department of Energy, 1000 Independence Avenue, S.W., Washington, DC 20585; and to the Office of Management and Budget (OMB), Paperwork Reduction Project (1910-0900), Washington, DC 20503.

U.S. Department of Energy Technical Standards Program Office c/o Performance Assurance Project Office P.O. Box 2009, Bldg. 9201-3

Oak Ridge, Tennessee 37831-8065 